\title{
Phylogenetic analysis of Jaagsiekte sheep retrovirus (JSRV) in Iraqi Awassi sheep
}

\author{
S.H. Al-Husseiny ${ }^{1}$, A. Jassim ${ }^{2}$, K.A. Mansour ${ }^{3}$ and Q.H. Kshash ${ }^{4}$ \\ Department of Internal and Preventive Medicine, College of Veterinary Medicine, University of Al-Qadisiyah, Iraq \\ Email: ${ }^{1}$ saad.ghmeiss@qu.edu.iq, ${ }^{2}$ assad.Jassim@qu.edu.iq, ${ }^{3}$ khalefa.mansour@qu.edu.iq, ${ }^{4}$ qassim.kshash@qu.edu.iq
}

(Received October 13, 2019; Accepted December 4, 2019; Available online July xx, 2020)

\begin{abstract}
Jaagsiekte sheep retrovirus (JSRV) infection in sheep results in contagious ovine pulmonary adenocarcinoma (OPA). The aim of this study was to detect the presence of JSRV in Iraqi Awassi sheep of Al-Qadisiyah Province using reverse transcription-PCR (RT-PCR). Lung secretion samples from 50 adult sheep (1.5 to 2-year-old) during 2016-2018 that were suffering from chronic respiratory distress with suspected clinical OPA were collected. RT-PCR assay for detection of JSRV was conducted using primers specific for its $382 \mathrm{bp}$ envelope protein gene. The results showed that 22 of the 50 (44\%) lung secretion samples were positive for JSRV. Phylogenetic tree analysis revealed the JSRV sequence detected in the local Iraqi sheep population was closely related to NCBI BLAST locus isolates KT279066.1 and KT279065.1. The study found that the JSRV disease is prevalent in the Iraqi Awassi sheep flocks and that the local JSRV isolate is genetically divergent from most other global isolates.
\end{abstract}

Keywords: Adenocarcinoma; Pulmonary; Retrovirus; RT-PCR; Sheep

DOI: 10.33899/ijvs.2019.126172.1255, (O2020, College of Veterinary Medicine, University of Mosul.

This is an open access article under the CC BY 4.0 license (http://creativecommons.org/licenses/by/4.0/).

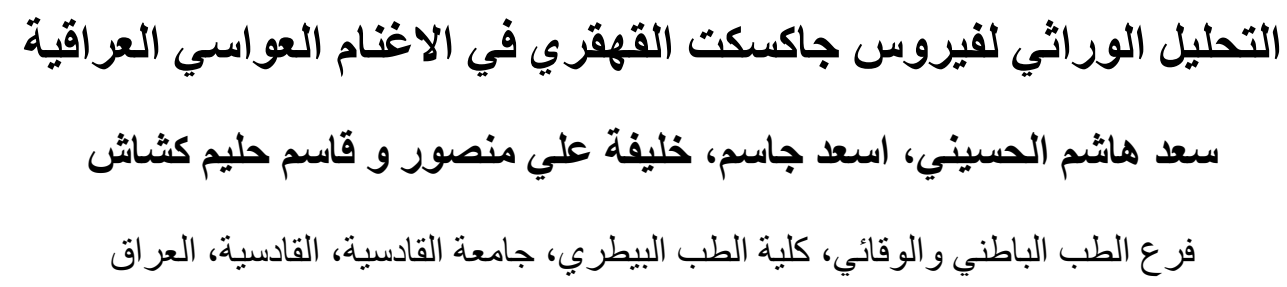

الخلاصة

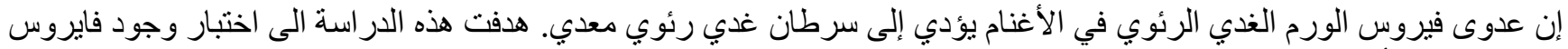

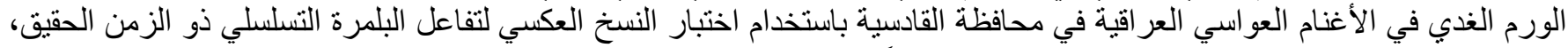

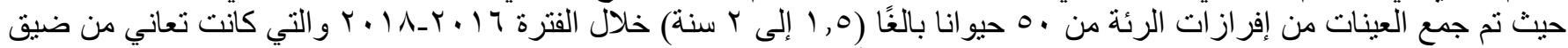

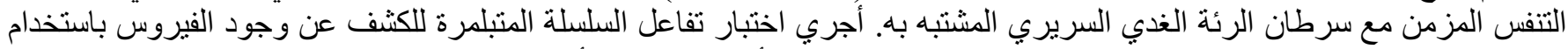

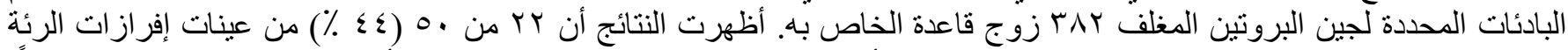

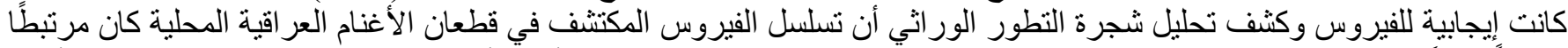

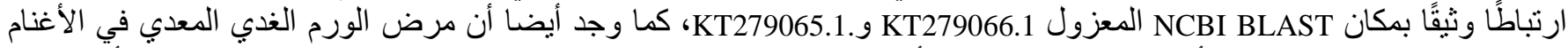
منتشر بشكل واسع في قطعان الأغنام العر اقية العو اسي وأن العزلة المحلية للفايروس منباينة وراثيا مع معظم العزلات التا العالمية الأخرى.

\section{Introduction}

Jaagsiekte sheep retrovirus is a Betaretrovirus and its genomic organization comprises only the important genes typical of retroviruses: gag, pro, pol, and env (1). It is thought that after the first viral infection, the virus may persist in white blood cells for few years before inducing neoplastic lesions by infecting pneumocytes and club cells 
upon reaching the lungs (2). During the 2017 epidemic OPA in Awassi sheep of Iraq, the first molecular and histopathological study occurred (3). Ovine pulmonary adenocarcinoma (OPA), caused by Jaagsiekte sheep retrovirus (JSRV), is characterized by the unvaryingly serious lung tumors that appear principally in mature sheep. OPA has a world-wide prevalence (4); as reported by the International Epizootic Office, it may have spread worldwide through international trade (5).

Greater incidence and infection rates are observed during the initial infection of the farm sheep, causing high economic losses in the farms. JSRV is an oncogenic retrovirus that affects epithelial cells of the lungs, especially the type II pneumocytes and club cells, and the initial infection proceeds to the formation of invasive bronchioloalveolar carcinoma (6). The clinical signs of JSRV infection are progressive emaciation and exerciseinduced chronic respiratory distress; the affected animals often lag in the flock, and thin mucus secretions from nostrils is observed. When the head is lowered, a copious foamy exudate or discharge from both nares occurs, and a moist rale is heard. However, coughing is not typically noticeable during auscultation (7). The clinical symptoms progress gradually, culminating in severe dyspnea; frequently, pneumonia due to secondary bacterial infection can occur, followed by death in a few days $(8,9)$.

In the presence of clinical respiratory signs or tumors, the diagnosis of OPA (10) and the detection of JSRV in lung secretions by RT-PCR (11) is easy. However, throughout the pre-clinical stage, it is difficult to detect the infection because of the absence of detectable circulating JSRV proteins and JSRV-specific antibodies external to the tumor (12). Thus, pre-clinical findings of JSRV infection in routine examinations are not possible.

The aim of this a study was to first report on the sequencing and phylogenetic analysis of JSRV in Iraqi Awassi

sheep.

\section{Materials and methods}

\section{Ethical approval}

The present study has approved by the Committee of Ethics of the College of Veterinary Medicine, University of Al-Qadisiyah, Iraq.

\section{Specimen collection}

A total of 150 animals from Awassi sheep were clinically inspected for the presence of clinical signs of JSRV infection, Lung secretion samples were collected randomly from the 50 adult affected animals $1.5-2$ year old during 2016-2018 that suffered previously from emaciation, chronic respiratory distress and non-responsive to treatment with antibiotics, and were suspected to have JSRV infection. Collected samples were immediately stored under sterile and cold conditions $2-8^{\circ} \mathrm{C}$ until the RT-PCR assays and additional tests.

\section{RNA extraction}

Viral RNA extractions from lung secretions were performed using the RNA extraction AccuZol ${ }^{\mathrm{TM}}$ " kit (Bioneer, Korea). In brief, $200 \mu \mathrm{l}$ of the lung secretion sample and $1 \mathrm{ml}$ of Trizol reagent were mixed together on a vortex for $1 \mathrm{~min}$, in a $1.5 \mathrm{ml}$ Eppendorf tube. Subsequently, $200 \mu \mathrm{l}$ of chloroform was added and mixed well for $15 \mathrm{Sec}$. Following $5 \mathrm{~min}$ of incubation on ice, the mixture was centrifuged at $12000 \mathrm{rpm}$ for $15 \mathrm{~min}$ at $4^{\circ} \mathrm{C}$. The supernatant was then transferred to a new tube and $500 \mu 1$ of isopropanol was added. The mixture was mixed by turning the tube over for 4-5 times and was incubated for $10 \mathrm{~min}$ at $4^{\circ} \mathrm{C}$.

The mixture was then centrifuged for $10 \mathrm{~min}$ at 12000 rpm, and the supernatant was discarded. Subsequently, the RNA pellet was washed with DEPC, resuspended in $1 \mathrm{ml}$ of $80 \%$ ethanol, and re-pelleted by centrifuging at $12000 \mathrm{rpm}$ for $5 \mathrm{~min}$ at $4^{\circ} \mathrm{C}$. Next, the supernatant was discarded and the RNA pellet was air-dried. Finally, $50 \mu 1$ of DEPC water was added for the elution of the RNA pellet, and tested by using NanoDrop (Bioneer, Korea). The extracted RNA was stored in a $-20^{\circ} \mathrm{C}$ freezer until RT-PCR was carried out.

\section{Reverse transcription-PCR}

Reverse transcription-PCR (RT-PCR) was carried out using a one-step RT-PCR kit (Bioneer, Korea, AccuPower ${ }^{(\mathbb{B})}$ RT-PCR PreMix). The specific primers, used for RT-PCR amplification of the gene encoding JSRV envelope protein was designed from the retrovirus isolate GVM-7 (envelope protein gene), partial CDS GenBank: (KT279065.1). The specific primer, and reverse transcription-PCR master mix was prepared according to the manufacturer's instruction summarized (13).

PCR amplification and reverse-transcription were performed in a one-tube reaction under the following thermo-cycler conditions: reverse transcriptase, one cycle at $50^{\circ} \mathrm{C}$ for $15 \mathrm{~min}$; initial denaturation, one cycle at $50^{\circ} \mathrm{C}$ for $15 \mathrm{~min}$; denaturation, 40 cycles at $95^{\circ} \mathrm{C}$ for $20 \mathrm{sec}$; annealing, 40 cycles at $58^{\circ} \mathrm{C}$ for $30 \mathrm{sec}$, final extension, $72^{\circ} \mathrm{C}$ for $5 \mathrm{~min}$; and a final hold at $4^{\circ} \mathrm{C}$. PCR product bands were visualized using a UV transilluminator (Vilber Lourmat, France).

The JSRV envelope protein gene-specific primer used in this study was ( $\mathrm{F}=\mathrm{CCG}$ GAA AGA GAT CGT ACC GT, $\mathrm{R}=$ TAA GGA ACA CAA GCT CGG GG). The master mix including $5 \mu \mathrm{L}$ Template, $2 \mu \mathrm{L}$ F-primer 10 pmol, $2 \mu \mathrm{L}$ Rprimer 10 pmol and $11 \mu \mathrm{L}$ DEPC.

\section{Sequencing and analysis}

PCR end products was sent to Bioneer, Korea for sequencing of the cDNA of the retrovirus using a specific 
(AB-DNA) sequencing system (gpB) forward primer. The resulting sequence and those of other global isolates obtained by NCBI blast search were aligned by the Arithmetic mean method and MEGA 7.0 to construct a phylogenetic tree.

\section{Results}

In this study, RT-PCR was used for the detection of (JSRV) using specific primers to produce 382 bp JSRV envelope protein gene. It was found that 22 out of the 50 lung secretion samples tested were positive for JSRV (Figure 1).

The nucleotide sequences of the local isolate were crosschecked using NCBI BLAST, to validate the RT-PCR result. The phylogenetic tree analysis revealed that the local Iraqi JSRV was closely related to NCBI BLAST locus Indian isolates KT279066.1 and KT279065.1, while other JSRVs were located out of the tree (Figure 2).

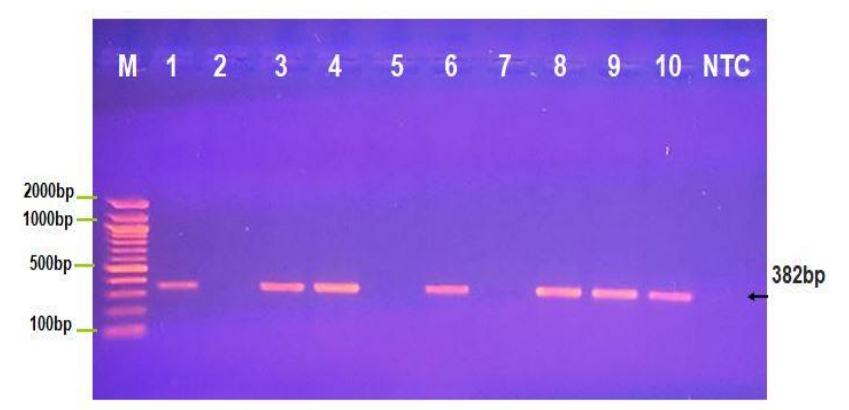

Figure1: the results of RT-PCR analysis of lung secretion samples for Jaagsiekte sheep retrovirus (JSRV) envelope protein gene; electrophoresis image of the RT-PCR products tested using JSRV-specific primers- Lanes 1, 3, 4, $6,8,9$, and 10 are positive for JSRV (382 bp long JSRV envelope protein gene); Lane 2, 5, and 7 show negative results; Lane (NTC) represents the negative control; Lane $\mathrm{M}$ represents the DNA ladder- molecular size marker (100$2000 \mathrm{bp}$ ).

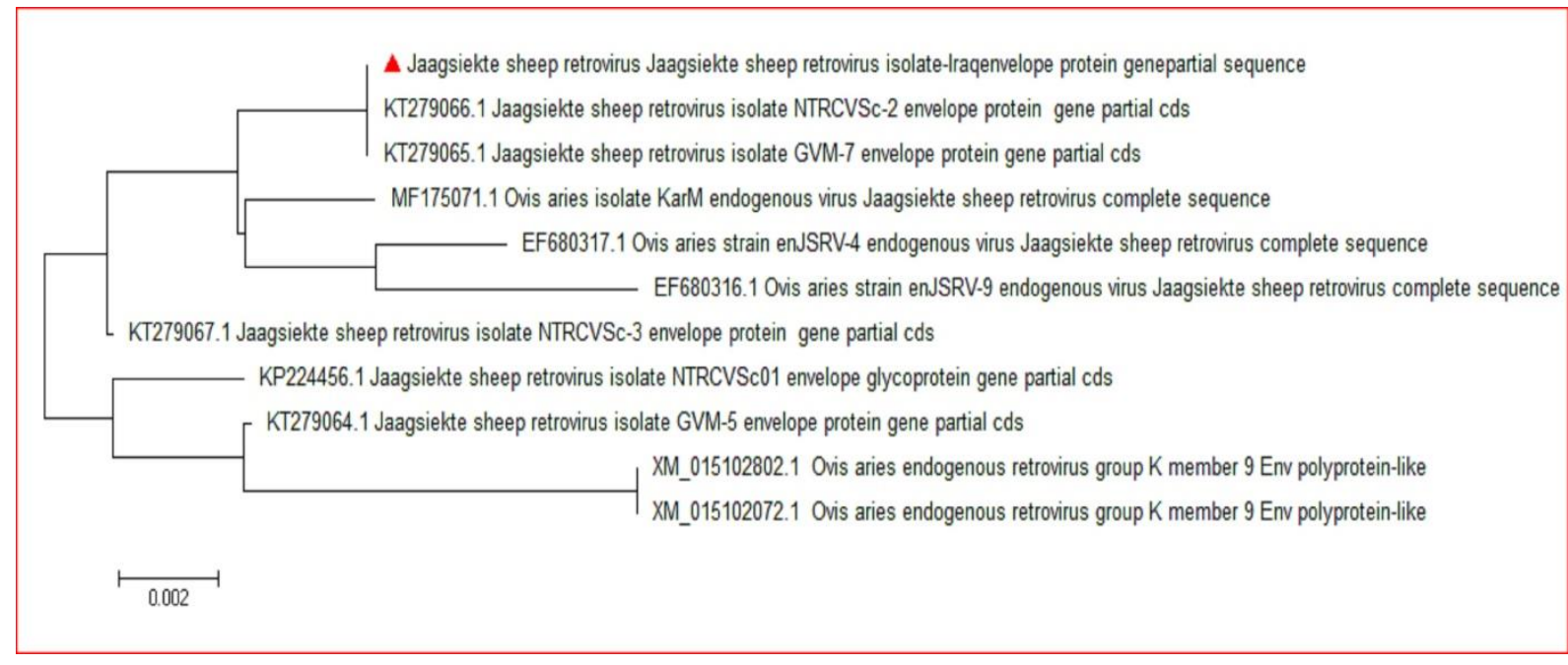

Figure 2: Phylogenetic tree analysis of Iraq isolates (JSRV) versus the other global reference strains obtained from GenBank which were 100\% homology with an Indian strain (KT279065.1 and KT279066.1) but divergent from other global strains.

Based on the NCBI BLAST sequence query alignment, the local Iraqi isolate of (JSRV) showed a high identity $(100 \%)$ with an Indian strain (KT279065.1 and KT279066.1), and 98\% sequence similarity with UK strain (MF175071.1) however divergent from other isolates.

\section{Discussion}

OPA was first recorded in Africa in 1825 (3), and was subsequently found among flocks in various countries $(14,15)$. The first molecular and histopathological recording of OPA in Iraq occurred during the 2017 respiratory distress epidemic cases and confirmed the occurrence of JSRV in different areas of Al-Qadisiyah Province. Moreover, the molecular results confirmed JSRV occurrence in Iraqi Awassi sheep $(15,16)$.

These recent studies were in agreement with (17-19). In the current study, samples were collected from affected sheep based on the typical clinical features of OPA. Using RT-PCR technique, the 382-bp JSRV DNA was identified in lung secretion samples obtained from adult sheep that were clinically identified to be suffering from the respiratory disorder. This result is in agreement with other studies $(20,21)$ that used PCR assay to diagnosis this 
virus. Eradicating OPA from a flock is difficult, because there is no available cost-effective assay for the detection of this virus and the infection cannot be detected in the preclinical stage by most diagnostic tests $(22,23)$.

The NCBI BLAST-based sequence enquiry showed that the Iraqi isolate evaluated in this study was closely related to the Indian isolates KT279066.1 and KT279065.1. We think that this may be due to the importation of sheep from India and other countries to Iraq.

Analysis of the phylogenetic tree revealed that, although the local JSRV isolate has high sequence similarity, is closely related, and clusters together with global isolates such as MF17507.1, EF680317.1, and KT279067, the local JSRV isolate exhibits divergence with other isolates (XM-01502802.1 and XM-015102072.1), which were located outside the generated phylogenetic tree. This finding is in agreement with previous reports $(24,25)$.

\section{Conclusions}

In conclusion, this study was the first report on sequencing and phylogenetic analysis of JSRV strains in Iraqi Awassi sheep which, will be of use for prospective studies of JSRV in Iraq, besides using lung secretions could be useful in the detection of disease by PCR.

\section{Authors' Contributions}

Conceptualization, SHA. and AJ.; Formal analysis, KAM; Funding acquisition, All authors; Investigation, SHA; Methodology, QHK; Project administration, AJ.; Software, KAM; Supervision, QHK; Validation, and Visualization, KAM and QHK.; Writing - original draft, SHA.; Writing - review \& editing, SHA and AJ. Funding: This research received no external funding.

\section{Acknowledgments}

The authors would like to thank the staff of Diagnostics Lab. College of Veterinary Medicine, University of AlQadisiyah, for providing the necessary facilities in this study. We would like to thank Editage (www.editage.com) for English language editing.

\section{Conflicts of interests}

The authors declare no conflict of interests.

\section{References}

1. De Las Heras M, González L, Sharp JM. Pathology of ovine pulmonary adenocarcinoma: Part of the current topics in microbiology and immunology book series. Berlin: SpringerVerlag; 2000. 25-54 p. 10.1007/978-3-642-55638-82.

2. Murgia C, Caporale M, Ceesay O, Di Francesco G, Ferri N, Varasano
V, de las Heras M, Palmarini M. Lung adenocarcinoma originates from retrovirus infection of proliferating type 2 pneumocytes during pulmonary post-natal development or tissue repair. PLoS Pathog. 2011;7(3):1-12. 10.1371/journal.ppat.1002014

3. Humann-Ziehank E, Renko K, Bruegmann ML, Devi VR, HewickerTrautwein M, Andreae A, Ganter M. Long-Term study of ovine pulmonary adenocarcinogenesis in sheep with marginal vs. sufficient nutritional selenium supply: results from computed tomography pathology immunohistochemistry jsrv-per and lung biochemistry. J Trace Elem Med Biol. 2013;27(4):391-399. 10.1016/J.JTEMB.2013.03.002

4. Griffiths DJ, Martineau HM, Cousens C. Pathology and pathogenesis of ovine pulmonary adenocarcinoma. J Comp Pathol. 2010;142(4):260-283. 10.1016/J.JCPA.2009.12.013

5. Hofacre A, Fan H. Jaagsiekte Sheep retrovirus biology and oncogenesis. Viruses. 2010;2:2618-2648. 10.3390/v2122618

6. Martineau HM, Cousens C, Imlach S, Dagleish MP, Griffiths DJ. Jaagsiekte sheep retrovirus infects multiple cell types in the ovine lung. J Virol. 2011;85(7):3341-3353. 10.1128/JVI.02481-10

7. Youssef G, Wallace WAH, Dagleish MP, Cousens C, Griffiths DJ. Ovine pulmonary adenocarcinoma: A large animal model for human lung cancer. ILAR J. 2015;56(1):99-115. 10.1093/ilar/ilv014

8. Nitta T, Hofacre A, Hull S, Fan H. Identification and mutational analysis of a rej response element in jaagsiekte sheep retrovirus RNA. J Virol. 2009;83(23):12499-12511. 10.1128/JVI.01754-08

9. Sharp JM, DeMartini JC. Natural History of JSRV in Sheep. Part of the current topics in microbiology and immunology book series. Berlin: Springer-Verlag; 2011. 55-79 p. 10.1007/978-3-642-55638-8

10. Sonawane GG, Tripathi BN, Kumar R, Kumar J. Diagnosis and Prevalence of ovine pulmonary adenocarcinoma in lung tissues of naturally infected farm sheep. Vet World. 2016;9(4):365-370. $\underline{10.14202 / \text { vetworld.2016.365-370 }}$

11. De las Heras M, Ortín A, Salvatori D, Pérez de Villareal M, Cousens C, Miguel Ferrer L, Miguel Cebrián L, García de Jalón JA, Gonzalez L, Michael Sharp JA. PCR Technique for the detection of jaagsiekte sheep retrovirus in the blood suitable for the screening of ovine pulmonary adenocarcinoma in field conditions. Res Vet Sci. 2005;79(3):259-264. 10.1016/J.RVSC.2005.02.003

12. Ortín A, Minguijón E, Dewar P, García M, Ferrer LM, Palmarini M, Gonzalez L, Sharp JM, De las Heras M. Lack of a specific immune response against a recombinant capsid protein of jaagsiekte sheep retrovirus in sheep and goats naturally affected by enzootic nasal tumour or sheep pulmonary adenomatosis. Vet Immunol Immunopathol. 1998;61(2-4):229-237. 10.1016/S01652427(97)00149-9

13. Jassim A, Al-Husseiny SH, Mansour KA, Kshash QH. First molecular diagnosis of ovine pulmonary adenocarcinoma in awassi sheep in iraq. Al-Qadisiyah J Vet Med Sci. 2017;16(1):112-117. 10.29079/vol16iss1art46

14. Sid N, El Houda Belalmi N, Benhamza L, Ouhida S, Ezine Zebiri M, Aydoğan A, Leroux C. First case report of enzootic nasal adenocarcinoma in 'Ouled Djellal' ewe in Algeria. Open Vet J. 2018;8(1):9-12. 10.4314/ovj.v8i1.3

15. Salvatori D, González L, Dewar P, Cousens C, de las Heras M, Dalziel RG, Sharp JM. Successful induction of ovine pulmonary adenocarcinoma in lambs of different ages and detection of viraemia during the preclinical period. J Gen Virol. 2004;85(11):3319-3324. 10.1099/vir.0.80333-0

16. Mansour KA, Al-Husseiny SH, Kshash QH, Jassim A. Clinicalhistopathological and molecular study of ovine pulmonary adenocarcinoma in awassi sheep in Al-Qadisiyah Province Iraq. Vet World. 2019;12(3):454-458. 10.14202/vetworld.2019.454-458

17. Zhang K, Kong H, Liu Y, Shang Y, Wu B, Liu X. Diagnosis and phylogenetic analysis of ovine pulmonary adenocarcinoma in china. Virus Genes. 2014;48(1):64-73. 10.1007/s11262-013-0988-x

18. Voigt K, Brügmann M, Huber K, Dewar P, Cousens C, Hall M, Sharp JM, Ganter M. PCR examination of bronchoalveolar lavage samples is 
a useful tool in pre-clinical diagnosis of ovine pulmonary adenocarcinoma (Jaagsiekte). Res Vet Sci. 2007;83(3):419-427. 10.1016/J.RVSC.2007.02.001

19. Bahari A, Ghannad MS, Dezfoulian O, Rezazadeh F, Sadeghi-Nasab A. Detection of Jaagsiekte Sheep Retrovirus in Apparently Healthy Sheep by Real-Time TaqMan PCR in Comparison with Histopathological Findings. J. Vet. Res. 2016; 60(1) 7-12. 10.1515/jvetres-2016-0002

20. Kycko A, Reichert M. PCR-Based Methods for detection of JSRV in experimentally and naturally infected sheep. Bull Vet Inst Pulawy. 2010;54:445-450.

21. Hoffmann B, Beer M, Reid SM, Mertens P, Oura CA, Van Rijn PA, Slomka MJ, Banks J, Brown IH, Alexander DJ. A review of RT-PCR Technologies used in veterinary virology and disease control: Sensitive and specific diagnosis of five livestock diseases notifiable to the world organisation for animal health. Vet Microbiol. 2009;139(12):1-23. 10.1016/J.VETMIC.2009.04.034

22. Summers C, Dewar P, van der Molen R, Cousens C, Salvatori D, Sharp JM, Griffiths DJ, Norval M. Jaagsiekte sheep retrovirus-specific immune responses induced by vaccination: A comparison of immunisation strategies. Vaccine. 2006;24 (11):1821-1829. 10.1016/J.VACCINE.2005.10.028

23. Lewis FI, Brulisauer F, Cousens C, McKendrick IJ, Gunn GJ. Diagnostic accuracy of PCR for Jaagsiekte sheep retrovirus using field data from 125 scottish sheep flocks. Vet J. 2011;187(1):104-108. 10.1016/J.TVJL.2009.10.024

24. Rama Devi V, Janardhan Yadav E, Sreenivasa RT, Satheesh K, Suresh P, Baby Manasa B. Nucleotide sequencing and phylogenetic analysis using pcr amplicons of U3 gene of jaagsiekte sheep retrovirus (JSRV) Detected in natural cases of ovine pulmonary adenocarcinoma in India. Open J Vet Med. 2014;4:267-275. 10.4236/ojvm.2014.411032

25. Lee AM, Wolfe A, Cassidy JP, Messam LM, Moriarty JP, O’Neill R, Fahy C, Connaghan E, Cousens C, Dagleish MP. First confirmation by PCR of jaagsiekte sheep retrovirus in ireland and prevalence of ovine pulmonary adenocarcinoma in adult sheep at slaughter. Ir Vet J. 2017;70(33):1-12. 10.1186/s13620-017-0111-z 